\title{
Low prevalence of most frequent pathogenic variants of six PARK genes in sporadic Parkinson's disease
}

\author{
Silvia García ${ }^{1}$, Luz Berenice López-Hernández ${ }^{1}$, Juan Antonio Suarez-Cuenca ${ }^{1,2}$, Marlene Solano-Rojas ${ }^{1,3}$, \\ Martha P. Gallegos-Arreola 4 , Olga Gama-Moreno ${ }^{1,5}$, Paulina Valdez-Anguiano ${ }^{1,6}$, Patricia Canto ${ }^{1}$, \\ Luis Dávila-Maldonado7, Carlos F. Cuevas-García ${ }^{8}$, Ramón Mauricio Coral-Vázquez ${ }^{6}$ \\ ${ }^{1}$ Centro Médico Nacional "20 de Noviembre”, Instituto de Seguridad y Servicios Sociales de los Trabajadores del Estado, México, D.F., \\ ${ }^{2}$ Hospital General de Zona No. 58, IMSS Estado de México; Mexican Group for Basic and Clinical Research in Internal Medicine, AC., \\ México D.F., ${ }^{3}$ Universidad Autónoma de Guerrero, U.A.C.Q.B, Guerrero, ${ }^{4}$ Centro de Investigación Biomédica de Occidente, Jalisco, \\ ${ }^{5}$ Universidad Autónoma de Guadalajara, ${ }^{6}$ Sección de Estudios de Posgrado e Investigación, Escuela Superior de Medicina, Instituto \\ Politécnico Nacional, México, D.F., ${ }^{7}$ Instituto de Ciencias Médicas y de la Nutrición Salvador Zubirán, México, D.F., ${ }^{8}$ Centro Médico \\ Nacional Siglo XXI, Instituto Mexicano del Seguro Social, México, D.F.
}

\begin{abstract}
Genetic variants that confer susceptibility to Parkinson's disease (PD) show unbalanced distribution among different populations; genetic predisposition to either familial or sporadic forms of PD in Mexican-mestizo population has not been comprehensively studied. The aim of the present study was to analyze genetic variants in six PARK genes in PD patients. In total 381 individuals (173 patients, 208 controls) were genotyped for p.Gly2019Ser and p.Gly2385Arg variants of LRRK2. The p.Gly2019Ser variant was present in two patients and one healthy control; the p.Gly2385Arg variant was not found. In a subgroup of early-onset PD (EOPD), MLPA analysis was done for PARKIN (PARK2), PINK1 (PARK6), DJ-1 (PARK7), LRRK2 (PARK8), SNCA (PARK1/4) and ATP13A2 (PARK9). We found a heterozygous deletion of exon 2 in PARK2 in the youngest patient of the early-onset group, who showed limited response to antiparkinsonian therapy. Although the changes Gly2019Ser and Gly2385Arg of LRRK2 are associated with PD in different populations; they may be a rare cause of PD in our population. Novel population-specific variants may underlie PD susceptibility in Mexican mestizos. Our study suggests that the heterozygous deletion of exon 2 in the PARK2 gene is a risk factor for EOPD.
\end{abstract}

Key words: Parkinson's disease, LRRK2, Mexican-mestizos, PARK2.

Communicating authors:

Ramón M. Coral-Vázquez, Sección de Estudios de Posgrado e Investigación, Escuela Superior de Medicina del Instituto Politécnico Nacional, Plan de San Luis y Díaz Mirón s/n, Col. Casco de Santo Tomas, C.P. 11340, México, D.F., México, phone: (5255) 57296300, ext. 62820, fax: (5255) 57296300, ext. 62820, e-mail: rmcoralv@gmail.com, rcoral@ipn.mx \& Luz Berenice López Hernández, División de Investigación Clínica, Subdirección de Enseñanza e Investigación, Centro Médico Nacional 20 de Noviembre, Instituto de Seguridad y Servicios Sociales de los Trabajadores del Estado, San Lorenzo 502, C.P. 03100, México, D.F., México, phone: 01525552005003 , fax: 015233363262 00, e-mail: Iblhmedgen@gmail.com 


\section{Introduction}

Parkinson's disease (PD) is a chronic progressive neurodegenerative disease that affects $1-2 \%$ of the population older than 65 years [14], diminishes quality of life and autonomy of patients [30]. Parkinson's disease is characterized by exacerbated loss of dopaminergic neurons of the substantia nigra pars compacta, which clinically expresses through tremor, rigidity, bradykinesia, postural instability and progressive impairment of the cognitive function [34].

Genetic factors that confer susceptibility to PD are still unclear although genetic variants in mitochondrial and nuclear genomes have been involved in this disease [17,37]; however, genetic variants in sezzzveral candidate genes (PARK genes) have been investigated in relation to both late and early onset presentations of the disease [late-onset PD (LOPD) and early-onset PD (EOPD), respectively). Among these genes, $L R R K 2$ and PARK2 are the most associated to LOPD and EOPD forms, respectively [31].

$\angle R R K 2$ encodes a multidomain protein, "dardarin" with kinase and GTPase activities. One of the most widely studied genetic variants within $L R R K 2$ is rs34637584 (c.6055G>A), (p.Gly2019Ser) located in the kinase domain $[14,26]$. In vitro studies showed an increased phosphotransferase activity due to this change [9]. It is worth noting that p.Gly2019Ser is the most common genetic variant of $L R R K 2$ in Caucasians; whereas another SNP, rs34778348 (p.Gly2385Arg) is considered a risk factor for PD in Asians $[6,18]$ The p.Gly2385Arg change in the C-terminal domain of $L R R K 2$ was shown to render neurons more susceptible to apoptosis under oxidative stress [35]. Thus, both variants are considered pathogenic although with different magnitude and biochemical effect.

On the other hand, PARK2 encodes a protein named "PARKIN", a component of an enzyme complex within the ubiquitin-proteasome system, which targets proteins for degradation [39]. Mutations in PARK2 are highly associated to familial EOPD; up to $18 \%$ of patients present mutations in this gene, and only $5 \%$ of them present in the homozygous state [21,27].

Interestingly, a skewed distribution of genetic variants of PARK genes was previously described; some authors suggested that ethnicity may play a role as a modifying factor of pathogenicity of $L R R K 2$ variants $[13,19,36]$. Interestingly, some mitochondrial variants and haplogroups are thought to modify the risk of developing PD $[15,38]$ by decreasing or increasing the penetrance of genetic variants in nuclear disease-genes (PARK genes). In this regard, it is known that the Mexican population was a result of genetic admixture among Amerindians, Caucasian and in a lesser extent, Africans [29] and, as in other Latin American populations [1], genetic factors predisposing to PD in Mexican-mestizos remain largely unknown $[23,28,40]$. Therefore, the aim of this study was to analyze the possible association between variants in PARK genes and PD by multiple screening as well as the weighing of their clinical relevance in Mexican-mestizo patients with sporadic PD (sPD).

\section{Material and methods \\ Study population}

The study was approved by the Human Research Committees of the participating institutions and informed written consent was obtained from all individuals. This is a cross-sectional study in which two-hundred fifteen Mexican-mestizo patients with sPD were consecutively recruited from February 2009 to June 2010, from four tertiary-care level hospitals in Mexico (Neurology Departments from Centro Médico Nacional "20 de Noviembre"-ISSSTE, Centro Médico Nacional Siglo XXI-IMSS, Instituto de Ciencias Médicas y de la Nutrición "Salvador Zubirán”, Mexico City; and División de Genética, Centro de Investigación Biomédica de Occidente-IMSS, Jalisco, Mexico); nevertheless, 42 patients were eliminated because of incomplete data. The diagnosis of SPD was performed by an experienced neurologist, based on the Queen Square Brain Bank criteria [16]. Early-onset PD was defined as onset at the age of 20 to 40 years. Two hundred and eight healthy individuals (controls) were analyzed; all were of Mexican-mestizo ethnic origin, and were blood bank donors and/or healthy spouses of PD patients without family history of PD or other neurological diseases. Cases with secondary parkinsonism were excluded.

\section{Mutation analysis}

Peripheral blood samples were obtained from patients and genomic DNA was isolated by the CTAB-DTAB method [11]. Real-time polymerase chain reaction $(P C R)$ allelic discrimination TaqMan assay (AB) was used for genotyping $L R R K 2$ variants. Briefly, PCR reactions contained 10-20 ng of DNA, $5.0 \mu \mathrm{l}$ of Maxima Probe qPCR Master Mix (2X), $0.25 \mu$ of primers and probes (10X) and $\mathrm{H}_{2} \mathrm{O}$ 
Silvia García, Luz Berenice López-Hernández, Juan Antonio Suarez-Cuenca, Marlene Solano-Rojas, Martha P. Gallegos-Arreola, Olga Gama-Moreno, Paulina Valdez-Anguiano, Patricia Canto, Luis Dávila-Maldonado, Carlos F. Cuevas-García, Ramón Mauricio Coral-Vázquez

to $10 \mu \mathrm{l}$, including the appropriate negative controls in all assays. For the p.Gly2019Ser variant, the assay was available from Applied Biosystem (assay ID: C_63498123_10), whereas for thep.Gly2385Arg polymorphism a novel hydrolysis probe assay was designed by our group. Primers sequences were as follows: forward 5'-GAAGTGTGGGATAAGAAAACTG-3' and reverse 5'-AGATGGTGCTGAGAAGCATTAC-3'. The probe for each allele was: wild-type VIC 5'-CTCTGT [G] GACTAATAGACTGCGTGCAC-3' and mutant FAM 5'-CTCTGT [A] GACTAATAGACTGCGTGCAC-3'. Real-time PCR was performed on a LightCycler 480 II (Roche Diagnostics $\mathrm{GmbH}$, Switzerland). Conditions for p.Gly2019Ser and p.Gly2385Arg p.Gly2385Arg polymorphisms were $95^{\circ} \mathrm{C}$ for $10 \mathrm{~min}$, and 40 cycles of amplification $\left(92^{\circ} \mathrm{C}\right.$ for $15 \mathrm{~s}$ and $60^{\circ} \mathrm{C}$ for $\left.1 \mathrm{~min}\right)$. For each cycle, the software determined the fluorescent signal from the VIC or FAM-labelled probe (Roche Applied Science, Mannheim, Germany). In order to confirm results of real-time genotyping, DNA was amplified by PCR and then sequenced (conditions and sequence of primers can be found in supplementary material).

For the EOPD subgroup, Multiplex-Ligation Dependent Probe Amplification (MLPA) was used to detect genetic variants in PARKIN (PARK2), PINK1 (PARK6), DJ-1 (PARK7), LRRK2 (PARK8), SNCA (PARK1/4) and ATP13A2 (PARK9) genes. The assay also detects gross gene deletions/duplications (P051-kit MRC-Holland) by direct hybridization and ligation of exon-specific half probes to DNA, ligated probes were further amplified by fluorescent multiplex PCR and capillary electrophoresis to reveal the altered copy number in the gene of interest. Data were analyzed with GeneMarker ${ }^{\circledR}$ software (SoftGenetics).

\section{Data analysis}

Sample size was estimated according to Armitage trend test taking into account allele risk frequency in Mexican mestizo population, prevalence of PD and the risk conferred by the pathogenic variant (http:// ihg.gsf.de/cgi-bin/hw/power2.pl [20/04/2013]) [32]. Age, age at onset, Hoehn \& Yahr scale and drug therapy requirement were analyzed through nonpaired $T$-test. Categorical variables such as gender, PD symptoms and antiparkinsonian drugs evaluation were analyzed through $\chi^{2}$. Deviations from Hardy-Weinberg equilibrium (HWE) were tested using the $\chi^{2}$ Pearson test (http://ihg.gsf.de/cgi-bin/hw/ hwa1.pl [20/04/2013]), $p$ value < 0.05 was consid- ered as statistically significant. SPSS software v. 18.0 (SPSS Inc., Chicago, IL, USA) was used for statistical analyses.

\section{Results}

In total 381 individuals were included, 173 patients with SPD constituted the study group (139 males and 34 females, aged $62.8 \pm 11.06$ [mean \pm standard deviation] years old, age at onset 57.8 \pm 14.27 ), whereas 208 healthy individuals constituted the control group (87 males and 121 females, aged $68.3 \pm 6.75$ years old; showing differences in gender proportion and age, $p<0.0001$ vs. the study group). The screening of $L R R K 2$ revealed the presence of the p.Gly2019Ser variant in two male patients with SPD with the age at onset at 66 and 56 years old and in one 66-year-old male from the control group (variants submitted to the Parkinson's disease Mutation Database, http://grenada.lumc.nl/LOVD2/TPI/home. php?select_db=LRRK2 [01/06/2012]). Genotype frequency was similar to expected values, according to Hardy-Weinberg equilibrium (HWE) test in both groups (HWE $P$ values $p=0.93$ for cases, $p=0.97$ for controls). Additionally, there was no case in our cohort carrying the p.Gly2385Arg variant, although DNA sequencing elicited the identification of a synonymous change p.Gly2385Gly in one patient (Fig. 1).

Since the prevalence of mutations in PARK genes is thought to be higher in young patients, we explored likely associations in a subgroup of 19 patients with EOPD showing particular clinical features, such as tremor 26.3\%, mental impairment 5.2\% ( $p<0.0002$ vs. the study group); more frequently prescribed with amantadine (89.5\%), antihistamines (78\%) and tricyclic acid antidepressants (78.9\%) ( $p<0.002$ vs. the study group); although with similar PD progression rate and treatment response (Hoehn \& Yahr scale "on-state" = $2.5 \pm 1.26, p=0.37$; "off-state" = $3.2 \pm 0.83, p=0.11$; “poor" response $10.5 \%, p=0.54$ ). MLPA screening of six PARK genes revealed a deletion of exon 2 in PARK2, the carrier was a female, and she was the youngest patient of this subgroup (30 years old with 2 years of PD symptoms), no tremor or mental impairment were found, but "poor" response to antiparkinsonian drug therapy was present in this case (L-Dopa, dopamimetics, anticholinergic and MAO inhibitors). The mutation p.Ala30Pro was also absent in all MLPA screened patients as revealed by the absence of peak signal. 
A

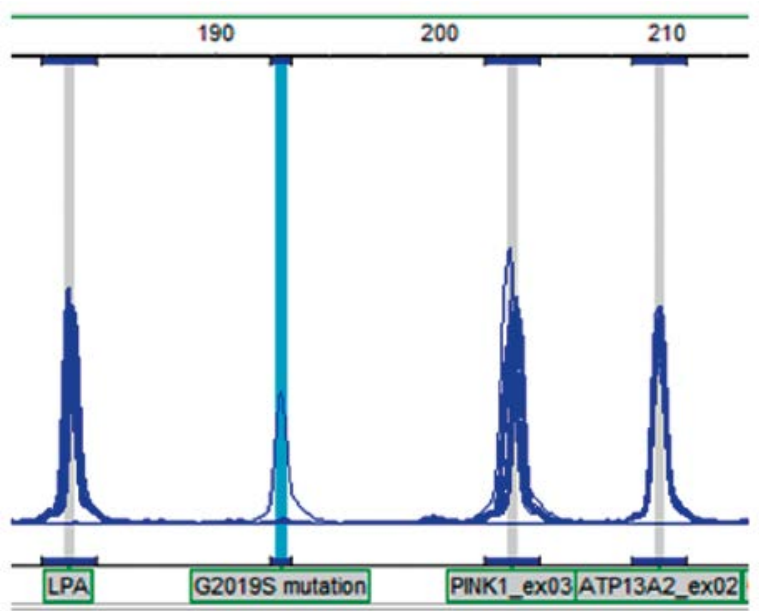

C

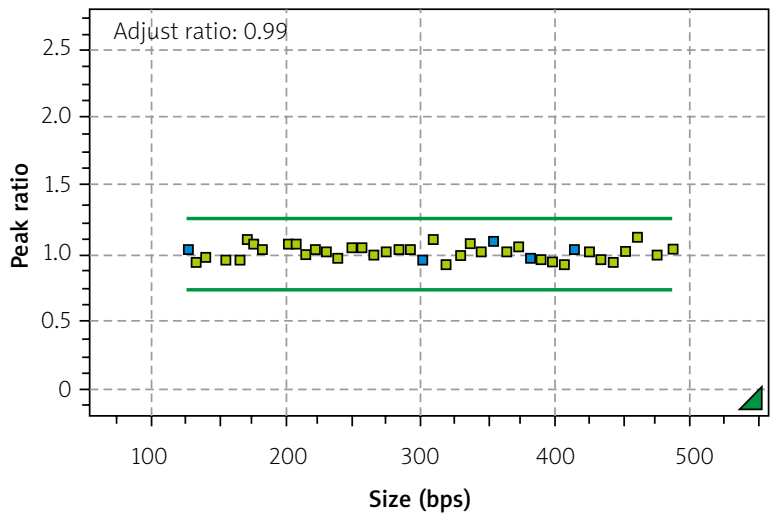

B

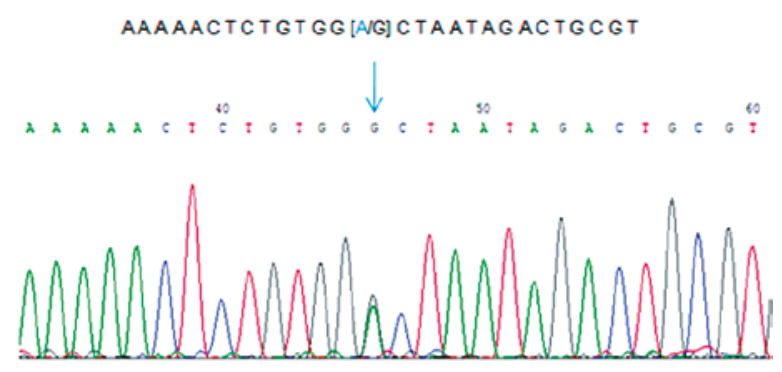

D

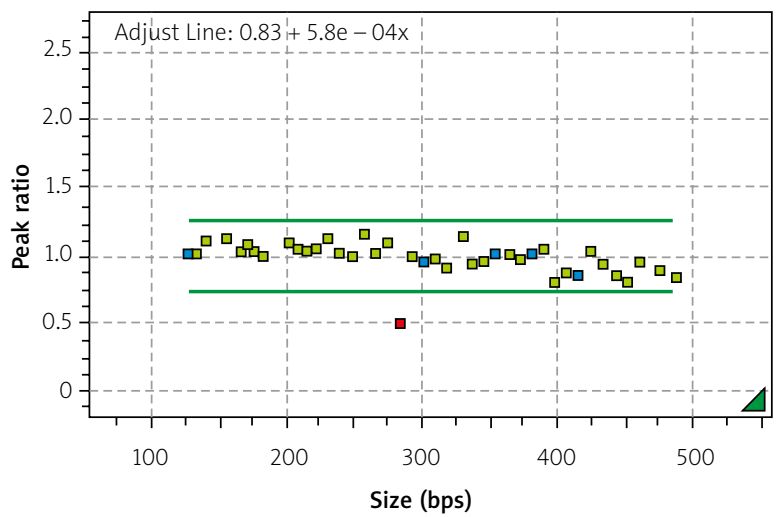

Fig. 1. A) MLPA peaks showing the p.Gly2019Ser mutation of LRRK2 as control. B) Sequencing of p.Gly2385Gly synonymous change. C) MLPA ratio analysis for PARK genes in a normal subject. D) MLPA ratio analysis showing a heterozygous deletion of exon 2 of PARKIN gene.

\section{Discussion}

Parkinson's disease is a complex neurodegenerative disorder in which genetic and environmental factors are involved. Ethnicity is thought to modify the effect of allelic variants associated to complex disorders; therefore, searching for prevalent mutations in PARK genes within specific populations is crucial to estimate susceptibility to PD [8]. This holds true especially for LRRK2 gene variants that have shown differential distribution among populations [18]. This also has potential in the pharmacogenetic field; since LRRK2 protein has been proposed as a therapeutic target for PD $[4,41]$. Nevertheless, biological mechanisms linking LRRK2 polymorphisms to neurodegeneration are still unclear. Interestingly, LRRK2 is expressed by immune cells and up-regulated following recognition of microbial structures [12]; allelic variants in LRRK2 and PARK2, have been associated to leprosy [3], celiac disease [7], Crohn's disease [20] and PD [2]; thus, there is a possible role for the immune system in the neurodegenerative process conferring population-specific susceptibility for PD.

It is worth mentioning that the highest frequency and penetrance of the LRRK2 p.Gly2019Ser change was found in North African Arabs (NA) and Ashkenazi Jewish (AJ) [13], in which mitochondrial haplogroup $\mathrm{H}$ carrying the $\mathrm{m} .4336 \mathrm{~T}>\mathrm{C}$ change associated to PD is also common [5]. Interestingly, a high frequency of celiac disease was also described in North Africans [10]. Thus, it is likely that the combination of the 
Silvia García, Luz Berenice López-Hernández, Juan Antonio Suarez-Cuenca, Marlene Solano-Rojas, Martha P. Gallegos-Arreola, Olga Gama-Moreno, Paulina Valdez-Anguiano, Patricia Canto, Luis Dávila-Maldonado, Carlos F. Cuevas-García, Ramón Mauricio Coral-Vázquez

changes m.4336T>C (haplogroup H) and p.Gly2019Ser confer susceptibility LRRK2 related diseases including PD. It is worth noting that all patients (with the exception of one - see supplementary material) and controls analyzed in this study did not have the variant m.4336T >C (unpublished data), which may result in a low penetrance of the variant p.Gly2019Ser of LRRK2, and a possible reason for the presence of this variant in an individual without PD.

A prior study of PARK2 and PD in Mexican-mestizos showed the absence of homozygous p.Arg366Trp and p.Asp394Asn polymorphisms; interestingly, two polymorphisms p.Ser167Asn and p.Val380Leu were in HWE disequilibrium; authors suggested a competing risk of death of variant carriers to explain such finding [23]. We speculate that HWE disequilibrium could be reminiscent evidence of prevalent diseases such as leprosy and tuberculosis in native populations of Mexico (http://www.salud.gob.mx/docprog/ estrategia_2/salud_y_nutricion.pdf [20/04/2013]). This would further support the involvement of PARK genes in immune response, although more in-depth research on this matter is required.

Although p.Gly2019Ser and p.Gly2385Arg are commonly found in Caucasians and Asians, respectively, our study showed a low prevalence on these variants in Mexican-mestizos; similarly to other reports of p.Gly2019Ser in our population [40] and from a population of the South of Spain [24]. This is concordant with the fact that first immigrants who arrived from Europe to Mexico came from the South of Spain [29]. Regarding the p.Gly2385Arg, it remains unexplored in most Latin American populations; here we showed the absence or very low frequency of this variant in our group of patients. We also found the p.Gly2385Gly synonymous change and despite it is not linked to PD, pathogenicity could not be excluded; some apparently neutral variants may have an impact on disease development [17]. Our results indicate that p.Gly2019Ser mutation may be a rare cause of PD in patients with different ethnical origin from NA and AJ; especially in the absence of mitochondrial variants associated to PD. Indeed, a recent study in Argentina showed that approximately 5.45\% (3/55) of PD patients had the p.Gly2019Ser heterozygous change and AJ ancestry, interestingly one of them presented also celiac disease [7] Although the frequency of p.Gly2019Ser change was present in two patients and one control, it should be taken into account that the cumulative risk of
PD for carriers of that variant is $51 \%$ at 69 years old [13], thus the 66-year-old individual from our control group still carries a remaining risk of developing PD. We strongly believe that genetic variants involved in the immune system and neurodegenerative diseases deserve further exploration. We speculate that the inner toxicity of dopamine production [37], exposure to pesticides that increase reactive oxygen species [33], plus increased oxidative stress caused by mitochondrial dysfunction may possibly cause protein oxidation and misfolding, and the subsequent formation of neoepitopes that trigger immune response mediated by $L R R K 2$ and PARK2. Convergent biological mechanisms and evolutive stories of populations could potentially contribute to elucidate genetic factors influencing PD susceptibility.

With regard of the analysis of the EOPD subgroup, after the screening of six PARK genes, mutation variants were rarely identified. However, our results support that PARK2 is the most common gene mutated in the EOPD group, and also supports the notion that the lower the age at onset, the more likely a gene mutation can be found in $P A R K 2$, as suggested by genetic screenings [22]. We cannot rule out a potential influence of the genotype since the patient carrying the PARK 2 mutation was the youngest one affected of the EOPD subgroup, achieving a limited therapeutic response, although slow clinical progression. The mechanism responsible for this phenotype may be related to the disruption of the reading frame of PARK2 gene, conferred by the deletion of exon 2 (c.8-?_171+?del); and although the deletion was heterozygous, this may be considered a risk factor for PD [25]. Thus, haploinsufficiency in PARKIN production could lead to a hampered turnover of damaged mitochondrion, due to inappropriate engagement of the autophagy pathway, caused by abnormal interactions between PINK1/PARKIN [39].

\section{Conclusions}

In the Mexican-mestizo population, the p.Gly2019Ser change could be a rare case of PD. The combination of variants p.Gly2019Ser and m.4336T>C was not present in any case and the p.Gly2385Arg was also absent. To our knowledge, this is the first work exploring the prevalence of pathogenic variants in various PARK genes in the Mexican-mestizo population. Our data support that PARK2 is the most common gene involved in EOPD and deletion of 
exon 2 even when heterozygous may be a risk factor. Although the most common pathogenic variants were scarce in our population, different nucleotide changes with similar biochemical properties cannot be excluded. The search for population-specific pathogenic variants in the PARK genes and in other related disease-related genes such as SNCA, MAO-B, and COMT [37] is important either to elucidate genetic unrevealed risk factors or to provide genetic counselling and discover novel therapeutic targets for PD.

\section{Acknowledgments}

We thank for the financial support from Consejo Nacional de Ciencia y Tecnología (CONACYT), México (Grant: SALUD-2009-C01-111692). We thank Z. Sánchez Mandujano for technical assistance, J.C. Zenteno and E. Pelcastre from the Instituto de Oftalmología, Fundación Conde de Valenciana for sequencing. Authors report no conflict of interest

\section{Disclosure}

Authors report no conflict of interest.

\section{Supplementary material - A novel genotyping assay for the $\mathrm{m} .4336 \mathrm{C}>\mathrm{T}$}

We designed a novel TaqMan probe for genotyping this mitochondrial change since RFLP is time consuming and sequencing is expensive compared to real time PCR.

In order to obtain a viable assay for genotyping of the mitochondrial change m.4336T >C, we searched for repetitive sequences (http://www.repeatmasker. org/). After that, appropriate conditions were chosen using Primer 3. Oligonucleotide sequences are shown below. The allele specific hydrolysis probes were: 5' (VIC)-TTCGATTCTCAT[A]GTCCTAG-3' (wild type) and 5'(FAM)-CGATTCTCAT[G]GTCCTAG-FAM (mutant).

The expected size of the amplified fragment is 88bp. Conditions for the reaction were: $1 \mu \mathrm{l}$ (10-20 ng) of DNA, $5.0 \mu \mathrm{l}$ of Maxima Probe qPCR Master Mix (2X), $0.25 \mu$ l of primers and probes (40X) and water for a final volume of $10 \mu \mathrm{l}$, including the appropriate negative controls in all assays. Real-time PCR was performed on a LightCycler 480 II (Roche Diagnostics $\mathrm{GmbH}$, Switzerland). The conditions for the reaction are $95^{\circ} \mathrm{C}$ for $10 \mathrm{~min}$, and 40 cycles of amplification $\left(92^{\circ} \mathrm{C}\right.$ for $15 \mathrm{~S}$ and $62^{\circ} \mathrm{C}$ for $\left.1 \mathrm{~min}\right)$. For each cycle, the software determined the fluorescent signal from VIC or FAM-labeled probes (Roche Applied Science,
Germany). Only one late-onset PD patient had the 4336C allele.

\section{References}

1. Benitez BA, Forero DA, Arboleda GH, Granados LA,Yunis JJ, Fernandez W, Arboleda $H$. Exploration of genetic susceptibility factors for Parkinson's disease in a South American sample. J Genet 2010; 89: 229-232.

2. Buschman E, Skamene E. Linkage of leprosy susceptibility to Parkinson's disease genes. Int J Lepr Other Mycobact Dis 2004; 72: 169-170.

3. Cardoso CC, Pereira AC, de Sales Marques C, Moraes MO. Leprosy susceptibility: genetic variations regulate innate and adaptive immunity, and disease outcome. Future Microbiol 2011; 6 : 533-549.

4. de Ynigo-Mojado L, Martin-Ruiz I, Sutherland JD. Efficient allele-specific targeting of LRRK2 R1441 mutations mediated by RNAi. PLoS One 2011; 6: e21352.

5. Feder J, Ovadia O, Glaser B, Mishmar D. Ashkenazi Jewish mtDNA haplogroup distribution varies among distinct subpopulations: lessons of population substructure in a closed group. Eur J Hum Genet 2007; 15: 498-500.

6. Fung HC, Chen CM, Hardy J, Singleton AB, Wu YR. A common genetic factor for Parkinson disease in ethnic Chinese population in Taiwan. BMC Neurol 2006; 6: 47

7. Gatto EM, Parisi V, Converso DP, Poderoso JJ, Carreras MC, Marti-Masso JF, Paisan-Ruiz C. The LRRK2 G2019S mutation in a series of Argentinean patients with Parkinson's disease: clinical and demographic characteristics. Neurosci Lett 2013; 537: 1-5.

8. Gaweda-Walerych K, Safranow K, Jasinska-Myga B, Bialecka M, Klodowska-Duda G, Rudzinska M, Czyzewski K, Cobb SA, Slawek J, Styczynska M, Opala G, Drozdzik M, Nishioka K, Farrer MJ, Ross OA, Wszolek ZK, Barcikowska M, Zekanowski C. PARK2 variability in Polish Parkinson's disease patients - interaction with mitochondrial haplogroups. Parkinsonism Relat Disord 2012; 18: 520-524.

9. Gloeckner CJ, Schumacher A, Boldt K, Ueffing M. The Parkinson disease-associated protein kinase LRRK2 exhibits MAPKKK activity and phosphorylates MKK3/6 and MKK4/7, in vitro. J Neurochem 2009; 109: 959-968.

10. Gujral N, Freeman HJ, Thomson AB. Celiac disease: prevalence, diagnosis, pathogenesis and treatment. World J Gastroenterol 2012; 18: 6036-6059.

11. Gustincich S, Manfioletti G, Del Sal G, Schneider C, Carninci P. A fast method for high-quality genomic DNA extraction from whole human blood. Biotechniques 1991; 11: 298-300, 302.

12. Hakimi M, Selvanantham T, Swinton E, Padmore RF, Tong Y, Kabbach G, Venderova K, Girardin SE, Bulman DE, Scherzer CR, LaVoie MJ, Gris D, Park DS, Angel JB, Shen J, Philpott DJ, Schlossmacher MG. Parkinson's disease-linked LRRK2 is expressed in circulating and tissue immune cells and upregulated following recognition of microbial structures. J Neural Transm 2011; 118: 795-808.

13. Healy DG, Falchi M, O'Sullivan SS, Bonifati V, Durr A, Bressman S, Brice A, Aasly J, Zabetian CP, Goldwurm S, Ferreira JJ, 
Tolosa E, Kay DM, Klein C, Williams DR, Marras C, Lang AE, Wszolek ZK, Berciano J, Schapira AH, Lynch T, Bhatia KP, Gas ser T, Lees AJ, Wood NW. Phenotype, genotype, and worldwide genetic penetrance of LRRK2-associated Parkinson's disease: a case-control study. Lancet Neurol 2008; 7: 583-590.

14. Healy DG, Wood NW, Schapira AH. Test for LRRK2 mutations in patients with Parkinson's disease. Pract Neurol 2008; 8: 381-385.

15. Huerta C, Castro MG, Coto E, Blazquez M, Ribacoba R, Guisasola LM, Salvador C, Martinez C, Lahoz CH, Alvarez V. Mitochondrial DNA polymorphisms and risk of Parkinson's disease in Spanish population. J Neurol Sci 2005; 236: 49-54.

16. Hughes AJ, Daniel SE, Ben-Shlomo Y, Lees AJ. The accuracy of diagnosis of parkinsonian syndromes in a specialist movement disorder service. Brain 2002; 125: 861-870.

17. Kochanski A. Pathogenic mutations and non-pathogenic DNA polymorphisms in the most common neurodegenerative disorders. Folia Neuropathol 2007; 45: 164-169.

18. Kumari U, Tan EK. LRRK2 in Parkinson's disease: genetic and clinical studies from patients. FEBS J 2009; 276: 6455-6463.

19. Liu X, Cheng R, Verbitsky M, Kisselev S, Browne A, Mejia-Sanatana H, Louis ED, Cote LJ, Andrews H, Waters C, Ford B, Frucht S, Fahn S, Marder K, Clark LN, Lee JH. Genome-wide association study identifies candidate genes for Parkinson's disease in an Ashkenazi Jewish population. BMC Med Genet 2011; 12: 104.

20. Liu Z, Lee J, Krummey S, Lu W, Cai H, Lenardo MJ. The kinase LRRK2 is a regulator of the transcription factor NFAT that mod ulates the severity of inflammatory bowel disease. Nat Immunol 2011; 12: 1063-1070.

21. Lohmann E, Periquet M, Bonifati V, Wood NW, De Michele G, Bonnet AM, Fraix V, Broussolle E, Horstink MW, Vidailhet $M$, Verpillat P, Gasser T, Nicholl D, Teive H, Raskin S, Rascol O, Destee A, Ruberg M, Gasparini F, Meco G, Agid Y, Durr A, Brice A. How much phenotypic variation can be attributed to parkin genotype? Ann Neurol 2003; 54: 176-185.

22. Lucking CB, Abbas N, Durr A, Bonifati V, Bonnet AM, de Broucker T, De Michele G, Wood NW, Agid Y, Brice A. Homozygous deletions in parkin gene in European and North African families with autosomal recessive juvenile parkinsonism. The European Consortium on Genetic Susceptibility in Parkinson's Dis ease and the French Parkinson's Disease Genetics Study Group. Lancet 1998; 352: 1355-1356.

23. Martinez HR, Gonzalez-Gonzalez H, Cantu-Martinez L, Rangel-Guerra R, Hernandez-Castillo CD, Vergara-Saavedra JJ, Ramos-Gonzalez MR, Cerda-Flores RM, Morales-Garza MA, Guerrero-Munoz MJ, Montes-de-Oca-Luna R, Saucedo-Cardenas O. PARKIN-coding polymorphisms are not associated with Parkinson's disease in a population from northeastern Mexico. Neurosci Lett 2010; 468: 264-266.

24. Moran JM, Castellanos-Pinedo F, Casado-Naranjo I, Duran-Herrera C, Ramirez-Moreno JM, Gomez M, Zurdo-Hernandez JM, Fuentes E, Ortiz-Ortiz MA, Moreno AD, Gonzalez-Polo RA Niso-Santano M, Bravo-Sanpedro JM, Perez-Tur J, Ruiz-Mesa LM, Fuentes JM. Genetic screening for the LRRK2, G2019S and R1441 codon mutations in Parkinson's disease patients from Extremadura, Spain. Rev Neurol 2010; 50: 591-594.

25. Nuytemans K, Meeus B, Crosiers D, Brouwers N, Goossens D, Engelborghs S, Pals P, Pickut B, Van den Broeck M, Corsmit E,
Cras P, De Deyn PP, Del-Favero J, Van Broeckhoven C, Theuns J. Relative contribution of simple mutations vs. copy number variations in five Parkinson disease genes in the Belgian population. Hum Mutat 2009; 30: 1054-1061.

26. Paisan-Ruiz C, Lang AE, Kawarai T, Sato C, Salehi-Rad S, Fisman GK, Al-Khairallah T, St George-Hyslop P, Singleton A, Rogaeva E. LRRK2 gene in Parkinson disease: mutation analysis and case control association study. Neurology 2005; 65 : 696-700.

27. Poorkaj P, Nutt JG, James D, Gancher S, Bird TD, Steinbart E, Schellenberg GD, Payami H. Parkin mutation analysis in clinic patients with early-onset Parkinson [corrected] disease. Am J Med Genet A 2004; 129A: 44-50.

28. Ramirez-Jirano LJ, Ruiz-Sandoval JL, Jimenez-Gil FJ, Ramirez-Vega J, Vargas-Frutos E, Gallegos-Arreola MP. Frequency of the IVS4+66A-G polymorphism in the alpha-synuclein gene in patients with Parkinson's disease in north-western Mexico. Rev Neurol 2007; 44: 15-17.

29. Rubi-Castellanos R, Martinez-Cortes G, Munoz-Valle JF, Gonzalez-Martin A, Cerda-Flores RM, Anaya-Palafox M, Rangel-Villalobos H. Pre-Hispanic Mesoamerican demography approximates the present-day ancestry of Mestizos throughout the territory of Mexico. Am J Phys Anthropol 2009; 139: 284-294.

30. Santos-Garcia D, Abella-Corral J, Aneiros-Diaz A, Santos-Canelles H, Llaneza-Gonzalez MA, Macias-Arribi M. Pain in Parkinson's disease: prevalence, characteristics, associated factors, and relation with other non motor symptoms, quality of life, autonomy, and caregiver burden. Rev Neurol 2011; 52: 385-393.

31. Satake W, Nakabayashi Y, Mizuta I, Hirota Y, Ito C, Kubo M, Kawaguchi T, Tsunoda T, Watanabe M, Takeda A, Tomiyama H, Nakashima K, Hasegawa K, Obata F, Yoshikawa T, Kawakami H, Sakoda S, Yamamoto M, Hattori N, Murata M, Nakamura Y, Toda T. Genome-wide association study identifies common variants at four loci as genetic risk factors for Parkinson's disease. Nat Genet 2009; 41: 1303-1307.

32. Slager SL, Schaid DJ. Case-control studies of genetic markers: power and sample size approximations for Armitage's test for trend. Hum Hered 2001; 52: 149-153.

33. Songin M, Ossowska K, Kuter K, Strosznajder JB. Alteration of GSK-3beta in the hippocampus and other brain structures after chronic paraquat administration in rats. Folia Neuropathol 2011; 49: 319-327.

34. Tabakman R, Lecht S, Lazarovici P. Neuroprotection by monoamine oxidase B inhibitors: a therapeutic strategy for Parkinson's disease? Bioessays 2004; 26: 80-90.

35. Tan EK, Zhao Y, Skipper L, Tan MG, Di Fonzo A, Sun L, FookChong S, Tang S, Chua E, Yuen Y, Tan L, Pavanni R, Wong MC, Kolatkar P, Lu CS, Bonifati V, Liu JJ. The LRRK2 Gly2385Arg variant is associated with Parkinson's disease: genetic and functional evidence. Hum Genet 2007; 120: 857-863.

36. Tomiyama $\mathrm{H}$, Hatano $\mathrm{T}$, Hattori N. Clinical molecular genetics for PARK8 (LRRK2)]. Brain Nerve 2007; 59: 839-850.

37. Torkaman-Boutorabi A, Ali Shahidi G, Choopani S, Reza Zarrindast M. Association of monoamine oxidase $B$ and catechol-O-methyltransferase polymorphisms with sporadic Parkinson's disease in an Iranian population. Folia Neuropathol 2012; 50: 382-389. 
38. van der Walt JM, Nicodemus KK, Martin ER, Scott WK, Nance MA, Watts RL, Hubble JP, Haines JL, Koller WC, Lyons K, Pahwa R, Stern MB, Colcher A, Hiner BC, Jankovic J, Ondo WG, Allen FH Jr, Goetz CG, Small GW, Mastaglia F, Stajich JM, McLaurin AC, Middleton LT, Scott BL, Schmechel DE, Pericak-Vance MA Vance JM. Mitochondrial polymorphisms significantly reduce the risk of Parkinson disease. Am J Hum Genet 2003; 72: 804811.

39. Wild P, Dikic I. Mitochondria get a Parkin' ticket. Nat Cell Biol 2010; 12: 104-106.

40. Yescas P, Lopez M, Monroy N, Boll MC, Rodriguez-Violante M, Rodriguez $U$, Ochoa A, Alonso ME. Low frequency of common LRRK2 mutations in Mexican patients with Parkinson's disease. Neurosci Lett 2010; 485: 79-82.

41. Yun H, Heo HY, Kim HH, DooKim N, Seol W. Identification of chemicals to inhibit the kinase activity of leucine-rich repeat kinase 2 (LRRK2), a Parkinson's disease-associated protein. Bioorg Med Chem Lett 2011; 21: 2953-2957. 